Keywords: pancreatic cancer; pancreatic intraepithelial neoplasia; non-small-cell lung cancer; acinar to ductal metaplasia; oncogenic Kras; Kras-driven cancer; oncogenic Kras signalling; metabolism; glycolysis; glutaminolysis; PI3K; Pdk1; Akt; MAPK

\title{
Oncogenic KRAS signalling in pancreatic cancer
}

\author{
S Eser ${ }^{1,2}$, A Schnieke ${ }^{3}$, G Schneider ${ }^{1}$ and D Saur ${ }^{\star, 1,2}$ \\ ${ }^{1}$ Department of Internal Medicine II, Klinikum rechts der Isar, Technische Universität München, Ismaningerstr. 22, 81675 München, \\ Germany; ${ }^{2}$ German Cancer Consortium (DKTK) and German Cancer Research Center (DKFZ), Im Neuenheimer Feld 280, 69120 \\ Heidelberg, Germany and ${ }^{3}$ Livestock Biotechnology, Technische Universität München, Liesel-Beckmann Str. 1., 85354 Freising, \\ Germany
}

Pancreatic ductal adenocarcinoma (PDAC) is almost universally fatal. The annual number of deaths equals the number of newly diagnosed cases, despite maximal treatment. The overall 5-year survival rate of $<5 \%$ has remained stubbornly unchanged over the last 30 years, despite tremendous efforts in preclinical and clinical science. There is unquestionably an urgent need to further improve our understanding of pancreatic cancer biology, treatment response and relapse, and to identify novel therapeutic targets. Rigorous research in the field has uncovered genetic aberrations that occur during PDAC development and progression. In most cases, PDAC is initiated by oncogenic mutant KRAS, which has been shown to drive pancreatic neoplasia. However, all attempts to target KRAS directly have failed in the clinic and KRAS is widely assumed to be undruggable. This has led to intense efforts to identify druggable critical downstream targets and nodes orchestrated by mutationally activated KRAS. This includes context-specific KRAS effector pathways, synthetic lethal interaction partners and KRAS-driven metabolic changes. Here, we review recent advances in oncogenic KRAS signalling and discuss how these might benefit PDAC treatment in the future.

PANCREATIC DUCTAL ADENOCARCINOMA IS DRIVEN BY ONCOGENIC KRAS

Pancreatic ductal adenocarcinoma (PDAC), the predominant form of pancreatic cancer, develops via acinar-ductal metaplasia (ADM) and neoplastic precursor lesions, such as pancreatic intraepithelial neoplasia (PanIN), intraductal papillary mucinous neoplasia (IPMN), mucinous cystic neoplasia and atypical flat lesions (AFLs; Morris et al, 2010; Aichler et al, 2012). Mutationally activated KRAS is present in $>90 \%$ of PDAC and represents the most frequent $(>90 \%)$ and the earliest genetic alteration, being found in low-grade PanIN 1A lesions (Morris et al, 2010; Kanda et al, 2012).

The KRAS proto-oncogene encodes an $\sim 21 \mathrm{kDa}$ small GTPase, which cycles between GTP-bound active and GDP-bound inactive states. The switch to the active state is promoted by guanine nucleotide exchange factors (GEFs), which aid exchange of GDP for GTP. KRAS inactivation is mediated by GTPase-activating proteins (GAPs), which induce hydrolysis of GTP. Activating mutations of KRAS found in human PDAC (point mutations at codon G12 (98\% of all KRAS mutations in PDAC), G13 and Q61) impair intrinsic GTPase activity of the KRAS protein and can block the interaction between KRAS and GAPs. This leads to constitutive activation of KRAS and persistent stimulation of downstream signalling pathways that drive many of the hallmarks of cancer, sustained proliferation, metabolic reprogramming, anti-apoptosis, remodelling of the tumour microenvironment, evasion of the immune response, cell migration and metastasis (Pylayeva-Gupta et al, 2011).

Targeting of mutant $\mathrm{Kras}^{\mathrm{G} 12 \mathrm{D}}$ or $\mathrm{Kras}^{\mathrm{G} 12 \mathrm{~V}}$ specifically to the murine pancreas is sufficient to initiate development of ADM, PanINs, IPMNs and AFLs, which progress with long latency to invasive metastatic PDAC, thus recapitulating the human disease (Hingorani et al, 2003; Guerra et al, 2007; Seidler et al, 2008; Morris et al, 2010; Pylayeva-Gupta et al, 2011). The low frequency of spontaneous progression of precursor lesions to invasive PDAC suggests that additional genetic aberrations are needed for disease progression (Morris et al, 2010). Pancreatic intraepithelial neoplasia and PDAC development can indeed be accelerated in Kras-driven mouse models by introducing inactivating mutations in tumour suppressor genes Cdkn2a, Trp53, or Dpc4/Smad4,

*Correspondence: Professor D Saur; E-mail: Dieter.Saur@|rz.tum.de

Received 28 November 2013; revised 19 March 2014; accepted 26 March 2014; published online 22 April 2014

(c) 2014 Cancer Research UK. All rights reserved 0007-0920/14

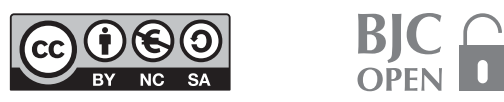


all of which occur frequently in human lesions as they progress to invasive PDAC (Jones et al, 2008; Morris et al, 2010; Biankin et al, 2012).

These mouse studies showed that oncogenic Kras is capable of initiating PDAC, but could not investigate whether continuous Kras activity is required for maintenance of PanINs and PDAC. Recently developed mouse models in which the Kras oncogene can be switched on and off have impressively demonstrated that continuous oncogenic Kras signalling is essential for both progression and maintenance of PDAC (Ying et al, 2012; Collins et al, 2012a). In addition, it became evident that sustained oncogenic Kras signalling is also necessary for the growth and maintenance of metastatic lesions (Collins et al, 2012b). However, individual tumour cells can remain dormant over a long time period after Kras inactivation. Accordingly, reactivation of oncogenic Kras in these dormant cancer cells leads to rapid disease progression (Collins et al, 2012b). This accords with studies of human pancreatic cancer cell lines that are addicted to oncogenic KRAS for sustained proliferation and survival (Zimmermann et al, 2013).

Together, these findings place oncogenic KRAS squarely at the top of the list of therapeutic targets. However, a subset of human PDAC cells is known to resist KRAS inactivation, a phenotype associated with an epithelial to mesenchymal transition (Singh et al, 2009). This highlights the importance of the genetic heterogeneity of human PDAC. Whole-exome and genome sequencing has revealed that human PDAC is an extremely heterogeneous disease with diverse molecular subtypes (Jones et al, 2008; Biankin et al, 2012; Cowley et al, 2013). Such in vitro findings therefore suggest that only a subset of pancreatic cancer patients will benefit from KRAS inhibition. This view is supported by an outstanding gene expression profiling study, which revealed three distinct subtypes of pancreatic cancer. One, termed the 'classical subtype', represents $41.2 \%$ of the analysed pancreatic cancer cases, has high expression of epithelial genes, and was found to be strongly dependent on constitutive KRAS signalling (Collisson et al, 2011). The 'quasi-mesenchymal' and the 'exocrine-like' subtypes were found in $36.5 \%$ and $22.3 \%$, respectively (Collisson et al, 2011). These distinctions clearly have a broad impact on clinical practice, and it is vital that the molecular determinants be defined.

Because oncogenic KRAS drives PDAC maintenance, at least in a large subset of PDAC patients, there have been considerable efforts to develop direct inhibitors. However, all clinical attempts to directly interfere with KRAS oncoprotein activity have failed, and KRAS is still widely considered undruggable (Berndt et al, 2011). A new approach is to identify and characterise druggable crucial downstream effectors of oncogenic KRAS. We now focus on effector pathways of oncogenic KRAS that contribute to PDAC initiation, progression and maintenance and how these pathways can be addressed therapeutically.

\section{EFFECTOR PATHWAYS OF ONCOGENIC KRAS}

KRAS signalling is highly complex and dynamic, engaging various downstream effectors, such as canonical Raf/Mek/Erk, phosphatidylinositol 3-kinase (PI3K)/3-phosphoinositide-dependent protein kinase-1 (Pdk1)/Akt, RalGDS/p38MAPK, Rac and Rho, Rassf1, NF1, p120GAP and PLC- $\varepsilon$ (Castellano and Downward, 2011; Pylayeva-Gupta et al, 2011). It is believed that oncogenic KRAS signalling in PDAC passes through three major pathways: Raf/ Mek/Erk, PI3K/Pdk1/Akt and the Ral guanine nucleotide exchange factor pathway (Lim et al, 2005; Feldmann et al, 2010; Collisson et al, 2012; Eser et al, 2013).

Recent findings in mice showed that pancreatic cancer initiation, progression and maintenance depend on tumour cell autonomous
Kras-PI3K-Pdk1 signalling. Pancreas-specific expression of PIK3CA ${ }^{\mathrm{H} 1047 \mathrm{R}}\left(\mathrm{p} 110 \alpha^{\mathrm{H} 1047 \mathrm{R}}\right)$, a constitutively active oncogenic class IA phosphatidylinositol 3-kinase, in Ptfla-positive cells enabled selective activation of the PI3K/Pdk1/Akt pathway and phenocopied Kras ${ }^{\mathrm{G} 12 \mathrm{D}}$-driven pancreatic carcinogenesis with striking similarity. In this model, oncogenic signalling flowed through Pdk1 and Akt without cross-activation of Kras, showing that the PI3K-Pdk1 axis represents a pathway capable of inducing cell plasticity, ADM, PanIN and PDAC formation (Eser et al, 2013). It is important to mention that contrasting findings have been reported using another murine model. Expression of $\mathrm{p} 110 \alpha^{\mathrm{H} 1047 \mathrm{R}}$ in Pdx1-positive cells using a tamoxifen activatable Pdx1-CreER mouse line failed to induce PanIN and PDAC formation (Collisson et al, 2012). Different target cells of distinct Cre-driver lines, differences in recombination efficacy, or different expression and signalling levels of p110 $\alpha$ might explain these opposing results.

Importantly, genetic proof of the importance of PI3K-Pdk1 signalling was shown in the classical Kras ${ }^{\mathrm{G} 12 \mathrm{D}}$-driven PDAC model. Genetic inactivation of Pdk1 (PDPK1) completely blocked the development of ADM, PanIN and PDAC (Eser et al, 2013). This was evident in several mouse models using different Cre-driver lines, clearly demonstrating that the PI3K/Pdk1 pathway is essentially engaged by oncogenic Kras and needed for PDAC formation.

Collisson and colleagues showed that selective activation of the Raf-Mek-Erk pathway by expression of a conditional mutant oncogenic Braf ${ }^{V 600 E}$ allele in murine pancreas induces PanIN and PDAC development. In this model, activation of the oncogene resulted in a more aggressive phenotype with more PanINs compared with the classical Kras ${ }^{\mathrm{G} 12 \mathrm{D}}$ model (Collisson et al, 2012). Thus, activation of the canonical MAPK pathway at the level of Raf is sufficient to drive neoplastic changes in pancreas. However, the contribution of Braf to Kras-driven pancreatic carcinogenesis remains unclear. Interestingly, Craf has no role in PDAC development in the Ptf $1 a^{\text {Cre }}{ }^{+} ; L S L-K r a s{ }^{G 12 D /+}$ PDAC model, although it is known to be important for Kras ${ }^{\mathrm{G} 12 \mathrm{D}}$-driven nonsmall-cell lung carcinogenesis (Blasco et al, 2011; Karreth et al, 2011; Eser et al, 2013).

The Ral guanine nucleotide exchange factor (RalGEFs) pathway has also been implicated in pancreatic carcinogenesis and progression. RalGEFs, which load GTP to small GTPases of the RAS superfamily, are necessary for RAS-induced transformation of several human cell types (Lim et al, 2005). They activate the RAS-like small GTPases RAL-A and RAL-B, which function as mediators of tumour growth and metastasis in human PDAC cell lines, respectively (Lim et al, 2006). High levels of active GTPbound RAL-A and RAL-B have been found in human PDAC (Lim et al, 2006). Inhibition of cyclin-dependent kinase 5 (CDK5) had a marked anti-tumourigenic effect on KRAS mutant PDAC cell lines in vitro and in vivo, which was attributed to reduced RAS-RAL signalling (Feldmann et al, 2010). CDK5 inhibition also reduced levels of RHO-GTP and RAC-GTP in these cell lines (Feldmann et al, 2010). These proteins belong to the RAS superfamily of small GTPases and are deregulated in PDAC. Interestingly, Rac1 is dispensable for pancreas development, but has an important role in regulating the actin cytoskeleton during metaplastic transdifferentiation in the early stages of pancreatic carcinogenesis (Heid et al, 2011). However, expression of a constitutively active form of Racl without concomitant expression of oncogenic Kras does not induce pancreatic carcinogenesis (Eser et al, 2013).

\section{CONTEXT SPECIFICITY OF ONCOGENIC KRAS} SIGNALLING

The therapeutic efficacy of inhibitors that target distinct effector pathways of oncogenic KRAS is likely to vary significantly between 
KRAS-driven tumour types. Recent data show that different downstream effectors are engaged by the Kras oncoprotein in PDAC and non-small-cell lung cancer (NSCLC) (Eser et al, 2013). The concept of tissue- and context-specific oncogenic signalling is illustrated by the need for Craf in $\mathrm{KRAS}^{\mathrm{G} 12 \mathrm{D}}$-driven NSCLC (Blasco et al, 2011; Karreth et al, 2011), but not KRAS ${ }^{\mathrm{G} 12 \mathrm{D}}$-driven pancreatic carcinogenesis (Eser et al, 2013). Furthermore, KRAS $^{\mathrm{G} 12 \mathrm{D}}$-driven PDAC depends completely on signalling via the PI3K effector Pdk1, whereas KRAS ${ }^{\mathrm{G} 12 \mathrm{D}}$-driven NSCLC is unaffected by loss of $P d k 1$ (Eser et al, 2013). This has significant implications for clinical therapy. Indeed, previous pharmacological studies in PDAC and NSCLC have suggested tissue-specific differences in KRAS signalling. Engelman et al (2008) found no substantial response of Kras ${ }^{\text {Gi2D }}$-driven NSCLC to PI3K-mTOR inhibition by NPV-Bez235 in vivo. Although genetic ablation of the RAS/PIK3CA interaction induced regression of Kras-driven NSCLC in vivo, treatment with either a class IA PI3K inhibitor or a $\mathrm{p} 110 \alpha$ isoform-specific inhibitor alone showed modest antitumour effects (Castellano et al, 2013). However, when either one of these agents was combined with a Mek1/2 inhibitor, striking tumour shrinkage was observed (Engelman et al, 2008; Castellano et al, 2013). In pancreatic cancer, a clinically available inhibitor of class IA PI3Ks efficiently blocked tumour progression in Kras ${ }^{\mathrm{G} 12 \mathrm{D}}$ driven PDAC in vivo (Eser et al, 2013). Input from receptor tyrosine kinases (RTKs) in Kras mutant tumours also seems to be tissue dependent, because elimination of the epidermal growth factor receptor (EGFR) in a mouse model of $\mathrm{Kras}^{\mathrm{G} 12 \mathrm{D}}$-driven NSCLC failed to recapitulate the inhibitory effect seen on $\mathrm{Kras}^{\mathrm{G} 12 \mathrm{D}}$-driven PDAC initiation (Navas et al, 2012). Kras signalling is tissue specific, with the important implication that efficacy of a treatment cannot be extrapolated from one Krasdriven tumour type to another. Indeed, it is well known that BRAF-driven melanoma and colon cancer differ markedly in their response to targeted therapies (Chapman et al, 2011; Prahallad et al, 2012). In line with this view, Kras-driven NSCLC depends on coordinated input from the Ras oncogene as well as the insulin-like growth factor 1 receptor (IGF1R), but not EGFR (Molina-Arcas et al, 2013). Accordingly, EGFR was predominantly activated in Kras wild-type NSCLC (Molina-Arcas et al, 2013). These data underscore the need to define tissue- and context-specific molecular hubs and vulnerabilities to develop effective treatment strategies.

\section{CROSS-SIGNALLING AND SIGNALLING LOOPS}

It has recently been recognised that autocrine and paracrine signalling loops are important amplifiers of oncogenic Kras signalling in several tumour types (Ardito et al, 2012; Navas et al, 2012; Molina-Arcas et al, 2013).

As described above, different RTKs are engaged in Krasinitiated carcinogenesis in different tissue types, which might explain tissue specificity and the differential response to targeted therapies. In mouse models of PDAC, activation of EGFR by a Kras-induced autocrine-positive feedback loop is essential for Kras-induced ADM and initiation of PanIN lesions (Ardito et al, 2012; Navas et al, 2012). Although not understood in detail, this positive feedback loop is believed to intensify the level of Kras signalling up to a threshold necessary for transformation of pancreatic acinar cells (Ardito et al, 2012; Navas et al, 2012). However, additional genetic aberrations, such as functional loss of p53, frequently observed in human PDAC, lead to the development of PDAC even without EGFR expression in this model (Navas et al, 2012). How loss of p53 function uncouples Kras ${ }^{\text {G12D }}$ from EGFR input in the pancreas is currently unknown. It is also unclear whether EGFR signalling is important for PanIN progression and
PDAC maintenance. Treatment with the EGFR inhibitor Erlotinib has shown benefit in a subpopulation $(<10 \%)$ of PDAC patients (Moore et al, 2007). This raises the question whether a subset of human PDAC remains addicted to KRAS signalling amplification via EGFR. However, the response to Erlotinib could also be due to inhibition of 'off-target' kinases with a higher affinity for the drug compared with EGFR (Conradt et al, 2011).

Negative feedback loops and inhibitory cross-signalling between different KRAS downstream pathways have a role in health and disease. Under physiological conditions, these inhibitory circuits fine-tune the level of signalling in response to growth factors, providing an appropriate response to external stimuli. Interestingly, persistence of negative feedback is found in tumour cells and seems to represent a major selection pressure for mutations in modulators of these feedback programmes (Chandarlapaty, 2012). Furthermore, persistent feedback inhibition provides an explanation of oncogene addiction as hyperdependency on the oncoprotein to sustain a certain strength of pathway output that acts to counter intrinsic inhibition (Pratilas et al, 2009; Chandarlapaty, 2012). This has important implications for the design of targeted therapeutic strategies. Inhibition of oncoproteins or certain effector pathways might reduce negative feedback and actually increase signal output, as shown recently in BRAF mutant colon cancer (Prahallad et al, 2012). Selective inhibition of the BRAF oncoprotein reduced a negative feedback loop blocking EGFR. EGFR signalling was consequently activated allowing continued proliferation of colon cancer cells via EGFR-mediated PI3K/AKT pathway activation (Prahallad et al, 2012). This contrasts with BRAF mutated melanoma, where BRAF inhibition efficiently blocks MAPK activation without affecting EGFR activation (Chapman et al, 2011; Prahallad et al, 2012). The mechanisms leading to tissue-specific EGFR expression and activation have yet to be uncovered.

It has long been known that there is inhibitory crosstalk between the PI3K/AKT and MAPK pathways at the level of AKT and RAF that modulates proliferation in human cancer cells (Zimmermann and Moelling, 1999). This interaction was found to be highly complex depending on several parameters such as cell type, RTK input and time course of RTK activation (Moelling et al, 2002). A novel RTK-independent crosstalk between these two pathways was found in an intriguing study by Zmajkovicova et al (2013). They showed that Mek1, phosphorylated by Erk at T292, is essential for the activity of a MAGI1/Mek1/PTEN complex that negatively regulates PI3K signalling (Zmajkovicova et al, 2013). Therefore, inhibition of the MAPK pathway is likely to interfere with PTEN tumour suppressor function and might lead to PI3K pathway activation. Loss of PTEN function and subsequent activation of the PI3K pathway has been found in PDAC and shown to accelerate tumour formation in mouse models of pancreatic cancer by amplification of PI3K/Akt pathway activation (Ying et al, 2011). This leads to increased signalling of the $\mathrm{NF} \kappa \mathrm{B}$ survival pathway and pro-tumourigenic changes in the tumour microenvironment (Ying et al, 2011). These examples of crosssignalling between KRAS downstream pathways in cancer might provide the basis for understanding primary therapeutic resistance and tissue-specific signalling requirements in different tumour entities driven by identical oncogenes.

KRAS SIGNALLING, INFLAMMATION AND THE TUMOUR MICROENVIRONMENT

The tumour microenvironment has been implicated as a major player in PDAC and could conceivably determine tissue-specific signalling pathways by paracrine activation of specific cytokine receptors or RTKs. A prominent desmoplastic reaction is found in PDAC that distinguishes it from other KRAS-driven tumour 
entities such as NSCLC. Continuous KRAS signalling in the pancreas generates a fibro-inflammatory microenvironment that promotes neoplastic progression via paracrine stimulation, with activated fibroblasts, pancreatic stellate cells and immune cells playing a key role (Erkan et al, 2012; Collins et al, 2012a). Interestingly, this change in the microenvironment is directly tied to oncogenic Kras signalling, because inactivation of oncogenic Kras in early-stage pancreatic neoplasia completely reverses the fibrotic and inflammatory changes (Collins et al, 2012a).

Chronic inflammation caused by repeated and/or sustained pancreatic injury through environmental or genetic factors is known to increase pancreatic cancer risk substantially (Yadav and Lowenfels, 2013). Although incompletely understood, the sustained inflammatory micromilieu contributes to a compromised anti-tumour immune response through the infiltration of immunosuppressive regulatory $\mathrm{T}$ cells and myeloid-derived suppressor cells (Pylayeva-Gupta et al, 2011; Steele et al, 2013). In addition, these inflammatory stimuli activate stellate cells and fibroblasts, causing fibrotic remodelling of pancreatic tissue, which in turn enhances oncogenic Kras signalling (Pylayeva-Gupta et al, 2011). Indeed, expression of oncogenic Kras in the adult murine pancreas has been shown to cause neoplastic changes only in the context of pancreatic inflammation (Guerra et al, 2007). Thus, oncogenic Kras signalling is enhanced by inflammatory stimuli and also itself drives inflammation and desmoplasia in pancreatic neoplasia.

\section{METABOLIC REPROGRAMMING BY ONCOGENIC KRAS}

Nearly 100 years ago, Otto Warburg recognised that altered metabolism is a hallmark of cancer. Tumour cells metabolise about 10 times more glucose than lactate than do normal cells, a phenomenon now known as aerobic glycolysis or the Warburg effect (Warburg, 1956). Oncogenic KRAS drives metabolic reprogramming in tumour cells by increasing aerobic glycolysis (e.g., by increasing expression of glycolytic enzymes, such as Hk1, Hk2, Glut1, Pfkl and Ldha), an effect that might be exploited therapeutically (Ying et al, 2012). Pancreatic cancer cells also depend on a particular type of glutamine metabolism that differs substantially from normal cells, again offering a promising therapeutic target (Son et al, 2013). The identification of tumour-cell-unique and potentially targetable metabolic pathways is a new and exciting field. How soon this can translate into clinically applicable therapeutic strategies is, however, uncertain. Factors such as context specificity and PDAC heterogeneity will certainly be important.

\section{NOVEL TARGETED THERAPEUTIC STRATEGIES}

Conventional chemotherapy has limited effect in pancreatic cancer (Moore et al, 2007; Conroy et al, 2011; Von Hoff et al, 2013). The MAPK and PI3K/PDK1/AKT pathways represent exciting new targets for therapeutic intervention, especially because known inhibitors are already clinically available. More than 20 RAF/MEK/ ERK and more than $40 \mathrm{PI} 3 \mathrm{~K} / \mathrm{AKT}$ inhibitors are currently in clinical trials (www.clinicaltrials.gov). Blockade of PI3K signalling in established genetically engineered Kras ${ }^{\mathrm{G} 12 \mathrm{D}}$-driven tumours and patient-derived primary PDAC xenotransplantation models efficiently inhibits growth in vivo (Eser et al, 2013). Collisson et al (2012) found a potent cytostatic effect of MEK1/2 inhibition in orthotopically transplanted human and mouse PDAC cell lines. In line with the known crosstalk between the PI3K and MEK pathways in KRAS mutant cancer types, compensatory PI3K/AKT pathway activation was observed upon MEK1/2 inhibition in this study (Collisson et al, 2012). This could be overcome by combining MEK1/2 with AKT inhibition. Impressive results of such combination therapy have been obtained in preclinical studies in NSCLC (Engelman et al, 2008). The first clinical studies to evaluate the efficacy of dual-pathway inhibition in patients with advanced cancers have also shown promising effects on tumour growth. However, dual-pathway inhibition was significantly more toxic than single-agent therapy (Shimizu et al, 2012). This might be overcome by inhibition of tissue-specific effectors required for activation of both pathways. Downward and colleagues applied this concept in preclinical treatment studies of NSCLC by inhibiting IGF1R and MEK, achieving dual-pathway inhibition (Molina-Arcas et al, 2013). As IGF1R inhibitors showed less impact on KRAS wild-type cells in this study, they might also cause less toxic side effects. Whether dual MAPK/PI3K pathway inhibition is more effective against Kras-driven endogenous PDAC in vivo is thus a question of paramount importance.

Direct inhibition of the KRAS oncoprotein in PDAC is another hopeful strategy. So far, all attempts to develop inhibitors of KRAS post-translational modification, such as farnesyl- and geranyltransferase inhibitors that interfere with membrane association and subcellular localisation, have been unsuccessful in the clinic (Berndt et al, 2011). Yet, there are some promising new methods, including small molecule inhibitors that block SOS-mediated nucleotide exchange and thus KRAS activation (Maurer et al, 2012; Sun et al, 2012), and KRAS ${ }^{\mathrm{G} 12 \mathrm{C}}$ inhibitors that allosterically shift the affinity of KRAS to favour GDP over GTP (Ostrem et al, 2013). Inhibition of the interaction between KRAS and the prenyl-binding protein $\mathrm{PDE} \delta$ to suppress oncogenic RAS signalling by altering its localisation to endomembranes has also shown interesting results in human PDAC cells in vitro and in vivo (Zimmermann et al, 2013).

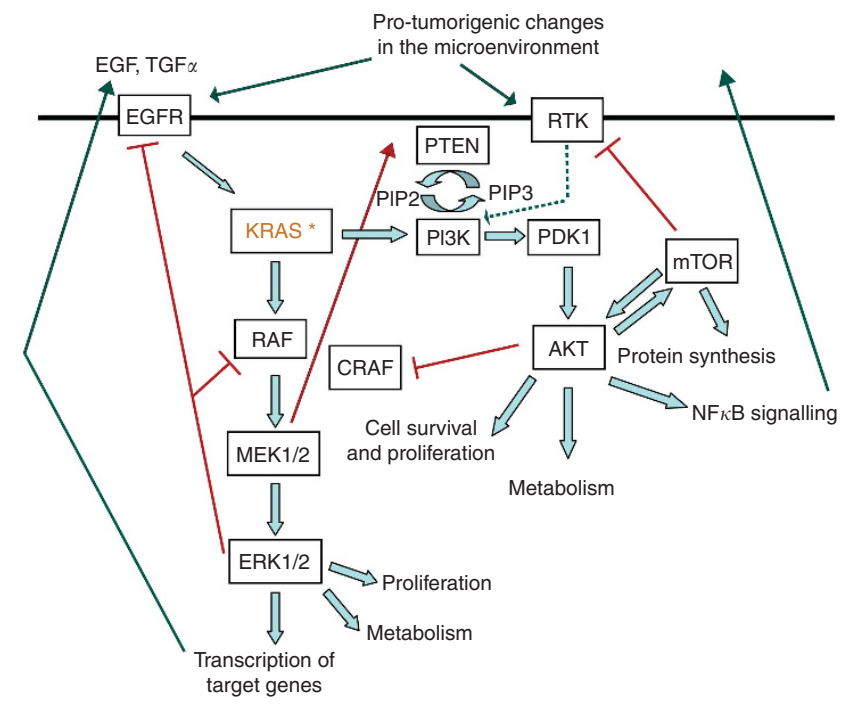

Figure 1. An overview of oncogenic KRAS-driven RAF/MEK/ERK and PI3K/PDK1/AKT signalling networks in pancreatic cancer. Mutationally activated oncogenic KRAS engages the PI3K-PDK1-AKT pathway to drive cancer initiation, progression and maintenance. Additionally, activated KRAS signals through the canonical mitogen-activated protein kinase pathway via RAF-MEK1/2-ERK1/2. KRAS activity is enhanced by positive feedback activation of the epidermal growth factor receptor (EGFR) and possibly by other receptor tyrosine kinases (RTKs) that are engaged by autocrine and paracrine stimuli. Negative feedback loops and inhibitory as well as activating cross-signalling exist at various levels. Activating pro-tumourigenic signalling connections are depicted as arrows in green; inhibitory anti-tumourigenic pathways are shown as solid lines headed by a vertical line in red. Arrows in red depict activating anti-tumourigenic feedback loops. The asterisk $\left(\mathrm{KRAS}^{*}\right)$ represents the mutational activation of KRAS. 
The identification of synthetic lethal interactions of oncogenic KRAS provides another means of targeting mutationally activated KRAS signalling. Defining such interactions depends on comprehensive screening efforts, as recently shown for the synthetic lethal interaction of BCL-XL with MEK inhibition in KRAS-driven cancers (Corcoran et al, 2013). However, concerns about the robustness of such screens require that the targets identified are validated independently.

\section{CONCLUDING REMARKS}

Oncogenic KRAS signalling is the main driving force behind PDAC. The signalling networks engaged by oncogenic KRAS are highly complex and characterised by the activation of several effector pathways. These are interconnected at various levels by cross-signalling and feedback loops (Figure 1). KRAS-driven signalling networks differ between tumour entities, such as PDAC, NSCLC and colon cancer, and most likely between subtypes of each entity. In different contexts KRAS signalling involves input from different upstream signals and engagement of different downstream effector pathways. Dissection and thorough understanding of these diverse signalling requirements is essential for the development of effective sub-entity-specific targeted strategies. These are urgently needed to improve the poor prognosis for patients suffering from KRAS-driven cancer.

\section{ACKNOWLEDGEMENTS}

We apologise to all colleagues whose work was not included in this review owing to space constraints. We thank Alexander Kind for his suggestions during the preparation of the manuscript. The authors are supported by Deutsche Forschungsgemeinschaft (DFG SA1374/4-1 to DS; SFB824, TP C9 to GS and DS; DFG SCHN971/3-1 to AS), German Cancer Consortium (DKTK) to DS, Deutsche Krebshilfe (\#108985 to DS and \#110230 to AS), the Helmholtz Alliance Preclinical Comprehensive Cancer Center (PCCC) to DS and Wilhelm-Sander Stiftung (Antrag Nr. 2012.84.1 to GS).

\section{REFERENCES}

Aichler M, Seiler C, Tost M, Siveke J, Mazur PK, Da Silva-Buttkus P, Bartsch DK, Langer P, Chiblak S, Durr A, Hofler H, Kloppel G, Muller-Decker K, Brielmeier M, Esposito I (2012) Origin of pancreatic ductal adenocarcinoma from atypical flat lesions: a comparative study in transgenic mice and human tissues. J Pathol 226: 723-734.

Ardito CM, Gruner BM, Takeuchi KK, Lubeseder-Martellato C, Teichmann N, Mazur PK, Delgiorno KE, Carpenter ES, Halbrook CJ, Hall JC, Pal D, Briel T, Herner A, Trajkovic-Arsic M, Sipos B, Liou GY, Storz P, Murray NR, Threadgill DW, Sibilia M, Washington MK, Wilson CL, Schmid RM, Raines EW, Crawford HC, Siveke JT (2012) EGF receptor is required for KRAS-induced pancreatic tumorigenesis. Cancer Cell 22: 304-317.

Berndt N, Hamilton AD, Sebti SM (2011) Targeting protein prenylation for cancer therapy. Nat Rev Cancer 11: 775-791.

Biankin AV, Waddell N, Kassahn KS, Gingras MC, Muthuswamy LB, Johns AL, Miller DK, Wilson PJ, Patch AM, Wu J, Chang DK, Cowley MJ, Gardiner BB, Song S, Harliwong I, Idrisoglu S, Nourse C, Nourbakhsh E, Manning S, Wani S, Gongora M, Pajic M, Scarlett CJ, Gill AJ, Pinho AV, Rooman I, Anderson M, Holmes O, Leonard C, Taylor D, Wood S, Xu Q, Nones K, Fink JL, Christ A, Bruxner T, Cloonan N, Kolle G, Newell F, Pinese M, Mead RS, Humphris JL, Kaplan W, Jones MD, Colvin EK, Nagrial AM, Humphrey ES, Chou A, Chin VT, Chantrill LA, Mawson A, Samra JS, Kench JG, Lovell JA, Daly RJ, Merrett ND, Toon C, Epari K, Nguyen NQ, Barbour A, Zeps N, Kakkar N, Zhao F, Wu YQ, Wang M, Muzny DM, Fisher WE, Brunicardi FC, Hodges SE, Reid JG, Drummond J, Chang K, Han Y, Lewis LR, Dinh H, Buhay CJ, Beck T,
Timms L, Sam M, Begley K, Brown A, Pai D, Panchal A, Buchner N, De Borja R, Denroche RE, Yung CK, Serra S, Onetto N, Mukhopadhyay D, Tsao MS, Shaw PA, Petersen GM, Gallinger S, Hruban RH, Maitra A, Iacobuzio-Donahue CA, Schulick RD, Wolfgang CL, Morgan RA, Lawlor RT, Capelli P, Corbo V, Scardoni M, Tortora G, Tempero MA, Mann KM, Jenkins NA, Perez-Mancera PA, Adams DJ, Largaespada DA, Wessels LF, Rust AG, Stein LD, Tuveson DA, Copeland NG, Musgrove EA, Scarpa A, Eshleman JR, Hudson TJ, Sutherland RL, Wheeler DA, Pearson JV, McPherson JD, Gibbs RA, Grimmond SM (2012) Pancreatic cancer genomes reveal aberrations in axon guidance pathway genes. Nature 491: 399-405.

Blasco RB, Francoz S, Santamaria D, Canamero M, Dubus P, Charron J, Baccarini M, Barbacid M (2011) c-Raf, but not B-Raf, is essential for development of K-Ras oncogene-driven non-small cell lung carcinoma. Cancer Cell 19: 652-663.

Castellano E, Downward J (2011) RAS Interaction with PI3K: more than just another effector pathway. Genes Cancer 2: 261-274.

Castellano E, Sheridan C, Thin MZ, Nye E, Spencer-Dene B, Diefenbacher ME, Moore C, Kumar MS, Murillo MM, Gronroos E, Lassailly F, Stamp G, Downward J (2013) Requirement for interaction of PI3-kinase p110alpha with RAS in lung tumor maintenance. Cancer Cell 24: 617-630.

Chandarlapaty S (2012) Negative feedback and adaptive resistance to the targeted therapy of cancer. Cancer Discov 2: 311-319.

Chapman PB, Hauschild A, Robert C, Haanen JB, Ascierto P, Larkin J, Dummer R, Garbe C, Testori A, Maio M, Hogg D, Lorigan P, Lebbe C, Jouary T, Schadendorf D, Ribas A, O’Day SJ, Sosman JA, Kirkwood JM, Eggermont AM, Dreno B, Nolop K, Li J, Nelson B, Hou J, Lee RJ, Flaherty KT, McArthur GA (2011) Improved survival with vemurafenib in melanoma with BRAF V600E mutation. N Engl J Med 364: 2507-2516.

Collins MA, Bednar F, Zhang Y, Brisset JC, Galban S, Galban CJ, Rakshit S, Flannagan KS, Adsay NV, Pasca di Magliano M (2012a) Oncogenic Kras is required for both the initiation and maintenance of pancreatic cancer in mice. J Clin Invest 122: 639-653.

Collins MA, Brisset JC, Zhang Y, Bednar F, Pierre J, Heist KA, Galban CJ, Galban S, di Magliano MP (2012b) Metastatic pancreatic cancer is dependent on oncogenic Kras in mice. PLoS One 7: e49707.

Collisson EA, Sadanandam A, Olson P, Gibb WJ, Truitt M, Gu S, Cooc J, Weinkle J, Kim GE, Jakkula L, Feiler HS, Ko AH, Olshen AB, Danenberg KL, Tempero MA, Spellman PT, Hanahan D, Gray JW (2011) Subtypes of pancreatic ductal adenocarcinoma and their differing responses to therapy. Nat Med 17: 500-503.

Collisson EA, Trejo CL, Silva JM, Gu S, Korkola JE, Heiser LM, Charles RP, Rabinovich BA, Hann B, Dankort D, Spellman PT, Phillips WA, Gray JW, McMahon M (2012) A central role for RAF-> MEK-> ERK signaling in the genesis of pancreatic ductal adenocarcinoma. Cancer Discov 2: 685-693.

Conradt L, Godl K, Schaab C, Tebbe A, Eser S, Diersch S, Michalski CW, Kleeff J, Schnieke A, Schmid RM, Saur D, Schneider G (2011) Disclosure of erlotinib as a multikinase inhibitor in pancreatic ductal adenocarcinoma. Neoplasia 13: 1026-1034.

Conroy T, Desseigne F, Ychou M, Bouche O, Guimbaud R, Becouarn Y, Adenis A, Raoul JL, Gourgou-Bourgade S, de la Fouchardiere C, Bennouna J, Bachet JB, Khemissa-Akouz F, Pere-Verge D, Delbaldo C, Assenat E, Chauffert B, Michel P, Montoto-Grillot C, Ducreux M (2011) FOLFIRINOX versus gemcitabine for metastatic pancreatic cancer. $N$ Engl J Med 364: 1817-1825.

Corcoran RB, Cheng KA, Hata AN, Faber AC, Ebi H, Coffee EM, Greninger P, Brown RD, Godfrey JT, Cohoon TJ, Song Y, Lifshits E, Hung KE, Shioda T, Dias-Santagata D, Singh A, Settleman J, Benes CH, MinoKenudson M, Wong KK, Engelman JA (2013) Synthetic lethal interaction of combined BCL-XL and MEK inhibition promotes tumor regressions in KRAS mutant cancer models. Cancer Cell 23: 121-128.

Cowley MJ, Chang DK, Pajic M, Johns AL, Waddell N, Grimmond SM, Biankin AV (2013) Understanding pancreatic cancer genomes. $J$ Hepatobiliary Pancreat Sci 20(6): 549-556.

Engelman JA, Chen L, Tan X, Crosby K, Guimaraes AR, Upadhyay R, Maira M, McNamara K, Perera SA, Song Y, Chirieac LR, Kaur R, Lightbown A, Simendinger J, Li T, Padera RF, Garcia-Echeverria C, Weissleder R, Mahmood U, Cantley LC, Wong KK (2008) Effective use of PI3K and MEK inhibitors to treat mutant Kras G12D and PIK3CA H1047R murine lung cancers. Nat Med 14: 1351-1356.

Erkan M, Adler G, Apte MV, Bachem MG, Buchholz M, Detlefsen S, Esposito I, Friess H, Gress TM, Habisch HJ, Hwang RF, Jaster R, Kleeff J, Kloppel G, Kordes C, Logsdon CD, Masamune A, Michalski CW, Oh J, 
Phillips PA, Pinzani M, Reiser-Erkan C, Tsukamoto H, Wilson J (2012) StellaTUM: current consensus and discussion on pancreatic stellate cell research. Gut 61: 172-178.

Eser S, Reiff N, Messer M, Seidler B, Gottschalk K, Dobler M, Hieber M, Arbeiter A, Klein S, Kong B, Michalski CW, Schlitter AM, Esposito I, Kind AJ, Rad L, Schnieke AE, Baccarini M, Alessi DR, Rad R, Schmid RM, Schneider G, Saur D (2013) Selective requirement of PI3K/PDK1 signaling for Kras oncogene-driven pancreatic cell plasticity and cancer. Cancer Cell 23: $406-420$.

Feldmann G, Mishra A, Hong SM, Bisht S, Strock CJ, Ball DW, Goggins M, Maitra A, Nelkin BD (2010) Inhibiting the cyclin-dependent kinase CDK5 blocks pancreatic cancer formation and progression through the suppression of Ras-Ral signaling. Cancer Res 70: 4460-4469.

Guerra C, Schuhmacher AJ, Canamero M, Grippo PJ, Verdaguer L, Perez-Gallego L, Dubus P, Sandgren EP, Barbacid M (2007) Chronic pancreatitis is essential for induction of pancreatic ductal adenocarcinoma by K-Ras oncogenes in adult mice. Cancer Cell 11: 291-302.

Heid I, Lubeseder-Martellato C, Sipos B, Mazur PK, Lesina M, Schmid RM, Siveke JT (2011) Early requirement of Rac1 in a mouse model of pancreatic cancer. Gastroenterology 141: 719-730, 730 e1-7.

Hingorani SR, Petricoin EF, Maitra A, Rajapakse V, King C, Jacobetz MA, Ross S, Conrads TP, Veenstra TD, Hitt BA, Kawaguchi Y, Johann D, Liotta LA, Crawford HC, Putt ME, Jacks T, Wright CV, Hruban RH, Lowy AM, Tuveson DA (2003) Preinvasive and invasive ductal pancreatic cancer and its early detection in the mouse. Cancer Cell 4: 437-450.

Jones S, Zhang X, Parsons DW, Lin JC, Leary RJ, Angenendt P, Mankoo P, Carter H, Kamiyama H, Jimeno A, Hong SM, Fu B, Lin MT, Calhoun ES, Kamiyama M, Walter K, Nikolskaya T, Nikolsky Y, Hartigan J, Smith DR, Hidalgo M, Leach SD, Klein AP, Jaffee EM, Goggins M, Maitra A, Iacobuzio-Donahue C, Eshleman JR, Kern SE, Hruban RH, Karchin R, Papadopoulos N, Parmigiani G, Vogelstein B, Velculescu VE, Kinzler KW (2008) Core signaling pathways in human pancreatic cancers revealed by global genomic analyses. Science 321: 1801-1806.

Kanda M, Matthaei H, Wu J, Hong SM, Yu J, Borges M, Hruban RH, Maitra A, Kinzler K, Vogelstein B, Goggins M (2012) Presence of somatic mutations in most early-stage pancreatic intraepithelial neoplasia. Gastroenterology 142: 730-733, e9.

Karreth FA, Frese KK, DeNicola GM, Baccarini M, Tuveson DA (2011) C-Raf is required for the initiation of lung cancer by K-Ras(G12D). Cancer Discov 1: 128-136.

Lim KH, Baines AT, Fiordalisi JJ, Shipitsin M, Feig LA, Cox AD, Der CJ, Counter CM (2005) Activation of RalA is critical for Ras-induced tumorigenesis of human cells. Cancer Cell 7: 533-545.

Lim KH, O’Hayer K, Adam SJ, Kendall SD, Campbell PM, Der CJ, Counter CM (2006) Divergent roles for RalA and RalB in malignant growth of human pancreatic carcinoma cells. Curr Biol 16: 2385-2394.

Maurer T, Garrenton LS, Oh A, Pitts K, Anderson DJ, Skelton NJ, Fauber BP, Pan B, Malek S, Stokoe D, Ludlam MJ, Bowman KK, Wu J, Giannetti AM, Starovasnik MA, Mellman I, Jackson PK, Rudolph J, Wang W, Fang G (2012) Small-molecule ligands bind to a distinct pocket in Ras and inhibit SOS-mediated nucleotide exchange activity. Proc Natl Acad Sci USA 109: 5299-5304.

Moelling K, Schad K, Bosse M, Zimmermann S, Schweneker M (2002) Regulation of Raf-Akt Cross-talk. J Biol Chem 277: 31099-31106.

Molina-Arcas M, Hancock DC, Sheridan C, Kumar MS, Downward J (2013) Coordinate direct input of both KRAS and IGF1 receptor to activation of PI3 kinase in KRAS-mutant lung cancer. Cancer Discov 3: 548-563.

Moore MJ, Goldstein D, Hamm J, Figer A, Hecht JR, Gallinger S, Au HJ, Murawa P, Walde D, Wolff RA, Campos D, Lim R, Ding K, Clark G, Voskoglou-Nomikos T, Ptasynski M, Parulekar W (2007) Erlotinib plus gemcitabine compared with gemcitabine alone in patients with advanced pancreatic cancer: a phase III trial of the National Cancer Institute of Canada Clinical Trials Group. J Clin Oncol 25: 1960-1966.

Morris JPt, Wang SC, Hebrok M (2010) KRAS, Hedgehog, Wnt and the twisted developmental biology of pancreatic ductal adenocarcinoma. Nat Rev Cancer 10: 683-695.

Navas C, Hernandez-Porras I, Schuhmacher AJ, Sibilia M, Guerra C, Barbacid M (2012) EGF receptor signaling is essential for k-ras oncogene-driven pancreatic ductal adenocarcinoma. Cancer Cell 22: 318-330.

Ostrem JM, Peters U, Sos ML, Wells JA, Shokat KM (2013) K-Ras(G12C) inhibitors allosterically control GTP affinity and effector interactions. Nature 503(7477): 548-551.
Prahallad A, Sun C, Huang S, Di Nicolantonio F, Salazar R, Zecchin D, Beijersbergen RL, Bardelli A, Bernards R (2012) Unresponsiveness of colon cancer to BRAF(V600E) inhibition through feedback activation of EGFR. Nature 483: 100-103.

Pratilas CA, Taylor BS, Ye Q, Viale A, Sander C, Solit DB, Rosen N (2009) V600E)BRAF is associated with disabled feedback inhibition of RAF-MEK signaling and elevated transcriptional output of the pathway. Proc Natl Acad Sci USA 106: 4519-4524.

Pylayeva-Gupta Y, Grabocka E, Bar-Sagi D (2011) RAS oncogenes: weaving a tumorigenic web. Nat Rev Cancer 11: 761-774.

Seidler B, Schmidt A, Mayr U, Nakhai H, Schmid RM, Schneider G, Saur D (2008) A Cre-loxP-based mouse model for conditional somatic gene expression and knockdown in vivo by using avian retroviral vectors. Proc Natl Acad Sci USA 105: 10137-10142.

Shimizu T, Tolcher AW, Papadopoulos KP, Beeram M, Rasco DW, Smith LS, Gunn S, Smetzer L, Mays TA, Kaiser B, Wick MJ, Alvarez C, Cavazos A, Mangold GL, Patnaik A (2012) The clinical effect of the dual-targeting strategy involving PI3K/AKT/mTOR and RAS/MEK/ERK pathways in patients with advanced cancer. Clin Cancer Res 18: 2316-2325.

Singh A, Greninger P, Rhodes D, Koopman L, Violette S, Bardeesy N, Settleman J (2009) A gene expression signature associated with 'K-Ras addiction' reveals regulators of EMT and tumor cell survival. Cancer Cell 15: 489-500.

Son J, Lyssiotis CA, Ying H, Wang X, Hua S, Ligorio M, Perera RM, Ferrone CR, Mullarky E, Shyh-Chang N, Kang Y, Fleming JB, Bardeesy N, Asara JM, Haigis MC, DePinho RA, Cantley LC, Kimmelman AC (2013) Glutamine supports pancreatic cancer growth through a KRAS-regulated metabolic pathway. Nature 496: 101-105.

Steele CW, Jamieson NB, Evans TR, McKay CJ, Sansom OJ, Morton JP, Carter CR (2013) Exploiting inflammation for therapeutic gain in pancreatic cancer. Br J Cancer 108: 997-1003.

Sun Q, Burke JP, Phan J, Burns MC, Olejniczak ET, Waterson AG, Lee T, Rossanese OW, Fesik SW (2012) Discovery of small molecules that bind to K-Ras and inhibit Sos-mediated activation. Angew Chem Int Ed Engl 51: 6140-6143.

Von Hoff DD, Ervin T, Arena FP, Chiorean EG, Infante J, Moore M, Seay T, Tjulandin SA, Ma WW, Saleh MN, Harris M, Reni M, Dowden S, Laheru D, Bahary N, Ramanathan RK, Tabernero J, Hidalgo M, Goldstein D, Van Cutsem E, Wei X, Iglesias J, Renschler MF (2013) Increased survival in pancreatic cancer with nab-paclitaxel plus gemcitabine. N Engl J Med 369: $1691-1703$.

Warburg O (1956) On the origin of cancer cells. Science 123: 309-314.

Yadav D, Lowenfels AB (2013) The epidemiology of pancreatitis and pancreatic cancer. Gastroenterology 144: 1252-1261.

Ying H, Elpek KG, Vinjamoori A, Zimmerman SM, Chu GC, Yan H, FletcherSananikone E, Zhang H, Liu Y, Wang W, Ren X, Zheng H, Kimmelman AC, Paik JH, Lim C, Perry SR, Jiang S, Malinn B, Protopopov A, Colla S, Xiao Y, Hezel AF, Bardeesy N, Turley SJ, Wang YA, Chin L, Thayer SP, DePinho RA (2011) PTEN is a major tumor suppressor in pancreatic ductal adenocarcinoma and regulates an NF-kappaB-cytokine network. Cancer Discov 1: 158-169.

Ying H, Kimmelman AC, Lyssiotis CA, Hua S, Chu GC, Fletcher-Sananikone E, Locasale JW, Son J, Zhang H, Coloff JL, Yan H, Wang W, Chen S, Viale A, Zheng H, Paik JH, Lim C, Guimaraes AR, Martin ES, Chang J, Hezel AF, Perry SR, Hu J, Gan B, Xiao Y, Asara JM, Weissleder R, Wang YA, Chin L, Cantley LC, DePinho RA (2012) Oncogenic Kras maintains pancreatic tumors through regulation of anabolic glucose metabolism. Cell 149: 656-670.

Zimmermann G, Papke B, Ismail S, Vartak N, Chandra A, Hoffmann M, Hahn SA, Triola G, Wittinghofer A, Bastiaens PI, Waldmann H (2013) Small molecule inhibition of the KRAS-PDEdelta interaction impairs oncogenic KRAS signalling. Nature 497: 638-642.

Zimmermann S, Moelling K (1999) Phosphorylation and regulation of Raf by Akt (protein kinase B). Science 286: 1741-1744.

Zmajkovicova K, Jesenberger V, Catalanotti F, Baumgartner C, Reyes G, Baccarini M (2013) MEK1 is required for PTEN membrane recruitment, AKT regulation, and the maintenance of peripheral tolerance. Mol Cell 50: 43-55.

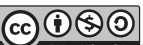

This work is licensed under the Creative Commons Attribution-NonCommercial-Share Alike 3.0 Unported License. To view a copy of this license, visit http://creativecommons. org/licenses/by-nc-sa/3.0/ 